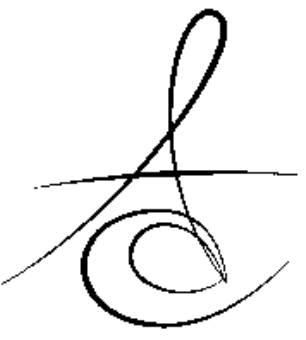

Yrd. Doç. Dr. Dilek GÜNAY CANPOLAT*

\section{DİŞ HEKİMLERİNİN KLİNİK UYGULAMALARINDA GENEL ANESTEZİYE YAKLAŞIMLARININ DEĞERLENDİRİLMESİ ${ }^{*}$}

\author{
EVALUATION OF APPROACHES OF THE DENTISTS TO GENERAL ANESTHESIA IN \\ THE CLINICAL PRACTICE ${ }^{*}$
}

\section{öz}

Amaç: Diş hekimliğinde genel anestezi uygulamaları, özellikle mental ve fiziksel engelli hasta grubunda kooperasyon güçlüğü yaşanması nedeniyle giderek yaygınlaşmaktadır. Bu çalışmanın amacı, diş hekimlerinin klinik uygulamalarında genel anesteziye bakış açıları ve yaklaşımlarını belirlemektir.

Gereç ve Yöntem: Araştırma tanımlayıcı nitelikli bir anket çalışması olarak planlandı. Anket formu, Kayseri ilindeki çeşitli kamu kurumları ve özel sektörde çalışan diş hekimleri, araştırma görevlileri ve diş hekimliği son sınıf öğrencilerine olmak üzere, toplam 120 diş hekimine ulaştırıldı. Anketi yanıtlamayı kabul eden 69 katıımcı çalışmaya dahil edildi. Veriler sayı ve yüzde olarak ifade edildi.

Bulgular: Dental tedavilerde genel anestezinin gerekli görülme oranı, diş hekiminin işini kolaylaştıran işlem ve konforlu bir uygulama olarak görülme oranları sırasıyla \%98.6, \%68.1, \%55.1 idi. Genel anestezi endikasyonlarl; \%37'si uyumsuz çocuk hasta, \%18.2'si mental retardasyon, $\% 14.5$ 'i dental fobi, \%12.7'si bulantı refleksi, $\% 10.9^{\prime}$ u uyumsuz erişkin hasta ve \%6.7' si işlem büyüklüğü olarak belirlendi. Alerjik hastalar genel anestezi altında mı daha güvenle tedavi edilirler? sorusuna \%62.3'ü hayır; epilepsi hastalarının tedavisini genel anestezi altında yapmayı tercih ederim önermesine $\% 52.2$ 'si hayır; dejeneratif kas hastalığı olan hastalarda genel anesteziden kaçınırım önermesine \%68.1'i evet yanıtını verdi.

Sonuç: Çalışma sonuçlarımıza göre; Kayseri ili ve çevresindeki diş hekimlerinin çoğu dental tedavilerde genel anestezi uygulamaları, risk ve komplikasyonları konusunda belirli düzeyde bilgi birikimi ve farkındalığa sahiptirler.

Anahtar Kelimeler: Diş hekimliği, Genel anestezi

\section{ABZTRACT}

Aim: General anesthesia becoming common especially in patients groups that have mental or physical disabilities due to noncooperation. Aim of this study was evaluated of the approaches and outlook of the dentists to general anesthesia in the clinical practice.

Material and Method: The research planned as a descriptive study. The survey form has been delivered to total 120 person who was working in public or private hospitals as a dentist or research assistants and the last class students in dentistry in Kayseri. Total 69 participants who accepted to fill the survey form included to the study. Data was given as number and percentage.

Result: General anesthesia was seen necessary, a procedure that facilitating the work of dentists and comfortable application at a rate of $98.6 \%, 68.1 \%, 55.1 \%$, respectively. General anesthesia indications were like this; $37 \%$ of them were noncoopere children, $18.2 \%$ of them has mental retardation, $14.5 \%$ of them has dental fobia, $12.7 \%$ of them has vomiting reflex, $10.9 \%$ of them were noncoopere adult patients and $6.7 \%$ of them has wide procedures. $62.3 \%$ of the participants answered ' $N o$ ' to the questions of can allergic patients treat securely. $52.2 \%$ the participants answered 'No' to the proposition of I prefered general anesthesia in epileptic patients, $68.1 \%$ of the participants answered 'Yes' to the proposition of I avoid from general anesthesia to the patients has degenerative muscle disease.

Conclusion: According to our study results, most of the dentists in Kayseri and surrounding have significantly knowledge and awareness about general anesthesia applications, complications and risks.

Key Words: General anesthesia; Dentistry

\footnotetext{
* Erciyes Üniversitesi, Ağız, Diş ve Çene Cerrahisi AD, Anesteziyoloji ve Reanimasyon Uzmanı, Kayseri

${ }^{* *}$ Erciyes Üniversitesi, Ağız, Diş ve Çene Cerrahisi AD, Kayseri

${ }^{* * *}$ Erciyes Üniversitesi, Kayseri

${ }^{\text {F} C ̧ a l ı s ̧ m a n ı n ~ b i r ~ b o ̈ l u ̈ m u ̈ ~ T A R K ~} 2015$ Kongresinde e-poster olarak sunulmuştur
} 


\section{GİRİŞ}

Diş hekimliğinde genel anestezi uygulamaları modern anestezi ile hemen hemen ayn tarihlerde başlar. Tarihte ilk inhalasyon anestezikleri olarak bilinen nitröz oksit ve dietil eter, dental girişimlerde analjezi amacıyla kullanılmıştır ${ }^{1}$. Zaman içerisinde, lokal anesteziklerin geliştirilmesi ile diş hekimliği uygulamalarında genel anesteziklerden uzaklaşılmıştır. Bilimse gelişmeler, insanların hayattan beklentilerini artırmış, dental tedavilerin de maksimum güvenli ve konforlu şartlarda yapılması gereğini beraberinde getirmiştir. Toplumun bir parçası olan mental ve bazı fiziksel engelli hasta grubunda, dental tedaviler sırasında sıklıkla kooperasyon güçlüğü yaşanması, genel anestezi uygulaması intiyacı doğurmaktadır². Ayrıca günümüzde, psikolojik problemleri hastalar, işlemin lokal şartlarda yapılamayacak kadar büyük olması, orofasiyal travma veya çene fraktürleri ${ }^{3,4,5}$, lokal anestezik alerjisi, kontrolsüz epilepsi gibi özellikli hastalar ${ }^{5}$ ve mental retarde ve nonkoopere hastaların geniş dental tedavileri $^{7,8}$ genel anestezi altında yapılmaktadır. Ayrıca genel anestezinin, diş hekimlerine işlem kolaylığı sağlayarak, tedavideki başarıyı artırdığı; değişik hasta gruplarında hasta memnuniyetini ve yaşam kalitesini iyileştirdiği gösterilmiştir ${ }^{8,9}$.

Genel anesteziye olan bu yöneliş, diş hekimlerinin genel anestezi ve riskleri hakkında yeterli bilgiye sahip olmalarını ve genel anestezi endikasyonu hasta seçimi konusunda dikkatli olmalarını gerektirmektedir. $\mathrm{Bu}$ çalışmanın birincil amacl; diş hekimlerinin genel anesteziye bakış açıları ve yaklaşımlarını belirlemek; ikincil amacı da genel anestezi endikasyonları, komPlikasyonları ve riskli hasta grupları hakkındaki farkındalıklarını değerlendirmektir.

\section{GEREC VE YÖNTEM}

Araştırma tanımlayıcı nitelikli bir anket çalışması olarak planlanıp, Erciyes Üniversitesi Etik Kurul onam alınarak, Kayseri ilinde gerçekleştirildi. Çalışma öncesi düzenlenen anket formu çalışmaya dahil edilmeyen 10 kişiye okutularak anlaşılabilirliği test edildi. Anket formu, Kayseri ilindeki çeşitli kamu kurumları ve özel sektörde çalışan diş hekimleri, araştırma görevlileri ve diş hekimliği son sınıf öğrencilerine olmak üzere, toplam 120 diş hekimine ulaştırıldı. Anketi yanıtlamayı kabul eden 69 katılımc çalışmaya dahil edildi. Anket soruları iki bölümde toplandı. Birinci bölümde kişisel bilgiler (yaş, cinsiyet, çalıştıkları kurum, çalışma süresi), ikinci bölümde de katılımcıların klinikte genel anestezi uygulamaları ve genel anestezi ile ilgili farkındalıklarını ölçmeyi hedefleyen toplam 17 soru yer aldı. Veriler sayı ve yüzde olarak ifade edildi.

\section{BULGULAR}

Çalışmaya \%40.6'sı (n=28) erkek, \%59.4'ü $(n=41)$ kadın olan toplam 69 kişi katıldı. Katılımcıların \%87'si (n=60) 20-29, \%11'i $(n=8) \quad 30-39, \quad \% 1$ 'i $(n=1.4) 40-50$ yaş aralıklarında olup, yaş ortalamaları 26 idi. Genel anesteziye yönlendirilen hastaların dental problemleri; \%34'ü $(n=24)$ diş çekimi, \%29.5' i $(n=21)$ dolgu ve tedavi, \%6.4' ü $(n=4)$ kist, \%14.7' si $(n=10)$ gömülü diş çekimi, \%10.3' ü $(n=7)$ ortognatik cerrahi, \%5.1'i ( $n=3)$ implant tedavisi şeklindeydi. Genel anestezi endikasyonları \%37'si $(n=26)$ uyumsuz çocuk hasta, \%18.2'si $(n=13)$ mental retardasyon, \%14.5'i $(n=10)$ dental fobi, \%12.7'si $(n=9)$ bulantı refleksi, $\% 10.9$ 'u $(n=8)$ uyumsuz erişkin hasta ve \%6.7' si $(n=5)$ işlemin lokal anestezi altında yapılama- yacak kadar geniş olması şeklindeydi. Katılımcıların görevleri ve klinik deneyim süreleri Tablo 1'de görül- mektedir. Diş hekimlerinin genel anesteziye yaklaşım- ları ile ilgili bazı soru ve ve önermelere verilen yanıtlar Tablo 2'de görülmektedir.

Tablo 1. Katılımcıların klinikteki görev ve deneyim süresi

\begin{tabular}{|l|c|c|}
\hline Diş hekim/erinin klinikteki görevi: & \% & n \\
\hline Öğretim Üyesi & 7.2 & 5 \\
\hline Pratisyen hekim & 8.7 & 6 \\
\hline Asistan & 40.6 & 28 \\
\hline Öğrenci & 43.5 & 30 \\
\hline Klinik deneyim süresi & \multicolumn{2}{|c|}{} \\
\hline$<1 y ı l ~$ & 5.8 & 4 \\
\hline $1-5$ yıl & 40.6 & 28 \\
\hline $5-10$ yıl & 71 & 49 \\
\hline$>10$ yll & 18.8 & 13 \\
\hline
\end{tabular}

\section{TARTIŞMA}

Çalışması sonuçlarımıza göre; diş hekimlerinin çoğu her ne kadar genel anestezinin işlem kolaylığı sağladığını düşünse de, öncelikli olarak lokal anesteziyi tercih etmektedirler. Çalışmamıza katılan diş hekimlerinin genel anestezi ve riskleri konusundaki farkındalıkları yüksektir.

Mental veya fiziksel hastalığı olan, kooperasyon kurulamayan ya da davranış terapisi ile ikna edileme-

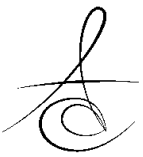


Tablo 2. Bazı soru ve önermelere verilen yanıtlar

\begin{tabular}{|l|c|c|c|c|}
\hline & $\begin{array}{c}\text { Evet \% } \\
(\boldsymbol{n})\end{array}$ & $\begin{array}{c}\text { Hayır \% } \\
(\boldsymbol{n})\end{array}$ & $\begin{array}{c}\text { Bazen } \\
\%(\boldsymbol{n})\end{array}$ & $\begin{array}{c}\text { Hiçbir } \\
\text { zaman } \\
\%(\boldsymbol{n})\end{array}$ \\
\hline $\begin{array}{l}\text { Dental tedavilerde genel } \\
\text { anestezi uygulaması gerekli } \\
\text { midir? }\end{array}$ & $\begin{array}{c}98.6 \\
(\mathrm{n}=68)\end{array}$ & $\begin{array}{c}1.4 \\
(\mathrm{n}=1)\end{array}$ & - & - \\
\hline $\begin{array}{l}\text { Dental tedavilerde genel } \\
\text { anestezi diş hekiminin işini } \\
\text { kolaylaştırır mı? }\end{array}$ & $\begin{array}{c}68.1 \\
(\mathrm{n}=47)\end{array}$ & $\begin{array}{c}0 \\
(\mathrm{n}=0)\end{array}$ & $\begin{array}{c}31.9 \\
(\mathrm{n}=22)\end{array}$ & - \\
\hline $\begin{array}{l}\text { Dental tedavilerde genel } \\
\text { anestezi hasta için konforlu } \\
\text { bir uygulama mıdır? }\end{array}$ & $\begin{array}{c}34.8 \\
(\mathrm{n}=24)\end{array}$ & $\begin{array}{c}10.1 \\
(\mathrm{n}=7)\end{array}$ & $\begin{array}{c}55.1 \\
(\mathrm{n}=38)\end{array}$ & $\begin{array}{c}0 \\
(\mathrm{n}=0)\end{array}$ \\
\hline $\begin{array}{l}\text { Hasta genel anestezi ile } \\
\text { dental tedavi istiyorsa, hiç } \\
\text { uğraşmam direk genel } \\
\text { anesteziye yönlendirim? }\end{array}$ & $\begin{array}{c}13 \\
(\mathrm{n}=9),\end{array}$ & $\begin{array}{c}52.2 \\
(\mathrm{n}=36)\end{array}$ & $\begin{array}{c}34.8 \\
(\mathrm{n}=24)\end{array}$ & - \\
\hline $\begin{array}{l}\text { Dental işlemler zaman } \\
\text { tasarrufu sağlar mı? }\end{array}$ & $\begin{array}{c}4.3 \\
(\mathrm{n}=3)\end{array}$ & $\begin{array}{c}68.1 \\
(\mathrm{n}=47)\end{array}$ & $\begin{array}{c}27.5 \\
(\mathrm{n}=19)\end{array}$ & - \\
\hline $\begin{array}{l}\text { Hastanızı hiç genel } \\
\text { anesteziye yönlendirdiniz } \\
\text { mi? }\end{array}$ & $\begin{array}{c}11.6 \\
(\mathrm{n}=8)\end{array}$ & $\begin{array}{c}2.9 \\
(\mathrm{n}=2)\end{array}$ & $\begin{array}{c}85.5 \\
(\mathrm{n}=59)\end{array}$ & - \\
\hline
\end{tabular}

yen normal sağlıklı çocukların tedavileri genel anestezi altında gerçekleştirilebilmekte ve bu zor hasta grubunda total oral rehabilitasyon sağlanabilmektedir ${ }^{9}$. Bu çalışmada; örneklemimizdeki diş hekimlerinin hemen hepsinin farklı nedenlerle genel anesteziye hasta yönlendirdiği ve genel anesteziyi dental tedavi uygulamalarında önemli bir gereksinim olarak gördükleri tespit edilmiştir. Genel anestezi tercih sebepleri arasında, en yüksek oranda diş çekimi ve uyumsuz çocuk hastalar yer alırken; en düşük oranda ise implant tedavisi ve işlemin lokal anestezi altında yapılamayacak kadar geniş olması tespit edilmiştir. Bu sonuç; diş çekimi işleminin hastalar tarafından ağrılı bir işlem olarak algılanması, lokal anestezi için kullanılan enjeksiyon iğnesine karşı gelişen korku hissi gibi pek çok faktörün etyolojisinde rol oynadığı dental fobiden kaynaklanıyor olabilir. Lee ve ark. ${ }^{10}$ çalışmalarında, uyumsuz veya ek sağlık problemi olan çocuk hastalarda, genel anestezi uygulamasının işlemi daha az karmaşık hale getirdiğini ve işlemle alakalı komplikasyon riskini azalttığını belirtmişlerdir. Bu anket çalışmasında da, diş hekimlerinin çoğunun genel anestezinin diş hekiminin işini kolaylaştıran, hem hasta hem de hekim için konforlu bir uygulama olduğunu düşündükleri tespit edilmiştir. Ayrıca ciddi öğürme refleksi olan hastalarda dental işlemleri gerçekleştirmek oldukça zor hatta imkansız olabilmektedir. İntravenöz anestezi yöntemi ile bu refleksin baskılanabileceği ve dental tedavilerde başarı sağlanabileceği bildirilmiştir ${ }^{11}$. Bizim çalışmamızda, öğürme refleksi nedeniyle genel anesteziye hasta yönlendirilme oranı \% 12 olarak belirlenmiştir.
Şüphesiz ki; genel anestezi avantajlarının yanın da pek çok dezavantajı da bünyesinde barındırır. Genel anestezi uygulaması sırasında işler her zaman yolunda gitmeyebilir ve bazen martalite ve morbidite ile sonuçlanabilir ${ }^{12}$. Bu nedenle, genel anestezi asla keyfi bir uygulama olmamalıdır. Hekimler hastayı iyi değerlendirmeli, genel anestezi endikasyonu koyarken kar-zarar hesabı yapmak suretiyle özenli olmalıdırlar. Bu anket çalışmasında katılımcılar, hastanın genel anestezi istemesi durumunda düşünmeden genel anes- teziye sevk ederim önermesine \%52.2 oranında hayır yanıtı verilmiştir. Bu sonuç, katılımcıların dental tedavi- ler için öncelikle klasik metodları tercih ettiklerinin ve genel anestezi komplikasyon ve riskleri konusunda farkındalıklarının yüksek olduğunun bir göstergesidir. Benzer şekilde, genel anestezinin katılımcılar tarafından zaman tasarrufu olarak görülmemesi oldukça doğru bir sonuç olarak karşımıza çıkmıştır. Genel anestezi planlanan hastalara riskleri anlatılmalı ve tüm cerrahi ve anestezi uygulamalarında olduğu gibi yazılı onam alınmalıdır ${ }^{13}$. Bu anket çalışmasında, katılımcılar hasta ve yakınlarını anestezinin komplikasyonları konusunda \%92.8 oranda ölüm dahil her türlü risk konusunda bilgilendirmeye özen gösterdiklerini bildirmişlerdir. Dental tedavilerin güvenli olarak yapılabilmesi için, genel anestezinin katostrofik riskleri unutulmamalıdır. Bu bağlamda, genel anestezi ameliyathanesi ve derlenme odası bulunmayan ve bir anestezi uzmanı ve beraberinde yetişmiş personelin ve gerekli ekipmanın olmadığı ortamlarda kesinlikle uygulanmamalıdır ${ }^{14,15}$.

Lokal anestezik ajanlar nadiren de olsa alerjik reaksiyonlara neden olabilirler ${ }^{16}$. Bazen hastanın lokal anesteziklere karşı alerji hikayesinin olması diş hekimlerini hastalarının işlemlerini yapabilmek için genel anesteziye yönlendirebilmektedir. Ancak unutulmamalıdır ki, genel anestezi indüksiyonu ve idamesi için çoklu anestezik ajanlar birlikte kullanılmaktadır. Hatta bazen, postoperatif analjezi sağlamak amacıyla genel anestezi sırasında lokal anesteziklerden de faydalanılmaktadır $^{17}$. Dolayısıyla alerjik bünyesi olan bir hasta, genel anestezi uygulamasıyla çoklu ilaca yani başka ifadeyle çoklu alerjene maruz kalabilmektedir. Dolayısıyla, çoklu ilaç maruziyeti artmış alerjik reaksiyon riski olarak yorumlanabilir. Bir prospektif çalışmada, Berroa ve $\operatorname{ark}^{18}$ perioperatif dönemde alerjik reaksiyon insidansının eski yıllara göre daha yüksek olduğunu ve şiddetinin orta düzeyde deri reaksiyonundan anaflaksiye kadar çeşitli düzeylerde olabileceğini rapor etmiş-

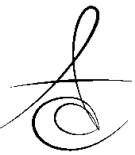


lerdir. Bu anket çalışmasında, katılımcıların \%62.3'ü kısmı alerji hikayesini genel anestezi endikasyonu olarak görmediklerini ifade etmiş olsa da, \%14.5 oranında endikasyon olarak görüldüğü tespit edilmiştir. Alerjik bünyesi olan hastalarda olası alerji riskine karşı her türlü medikal ve acil müdahale şartlarını hazır edip, gerekli tedbirler alındıktan sonra işlemin lokal anestez altında yapılması daha doğru bir yaklaşım olabilir. Hastanın bilinen bir lokal anesteziğe karşı alerji öyküsü varsa, o ajan ve onunla aynı gruptan olan lokal anestezikler kullanılmamalı, hatta mümkünse işlem öncesi bir alerji uzmanının önerilerinin alınıp o doğrultuda hareket edilmesi doğru yaklaşım olacaktır.

Diş hekimleri çalışma ofislerinde ve kliniklerinde epileptik nöbet gibi acil bir durumla karşılaşabilirler. Bu nedenle, bir diş hekimi epilepsi hastalığını iyi bilmeli ve nöbet geçiren hastaya zarar gelmemesi için gerekli tedbirleri almalıdır. Nöbetleri kontrol altında olan hastaların dental tedavileri işlemden önce nöbet ve ilaç kullanım öyküsünü öğrenip, gerekli tedbirleri almak suretiyle kliniklerde güvenle yapılabilir ${ }^{19,20}$. Ayrıca, literatürde stresin nöbeti tetikleyebileceği hatta stresli bir yaşamın epilepsi hastalığını başlatabileceğine dair bilgi mevcuttur ${ }^{21}$. Nöbetleri kontrol altında olmayan hastalarda, sedasyon veya genel anestezi uygulaması, hastayı stresin tetiklediği epileptik nöbetten koruyabilir diyebiliriz. Ancak, bunun yanında bazı anestezik ajanların nöbet eşiğini azaltıp nöbetleri tetikleyebileceğini de unutmamalıdır ${ }^{22}$. Bu çalışmadaki verilerimize göre, katılımcıların az bir kısmı epilepsi hastalarında genel anesteziyi tercih etmiş, çoğunluğu epilepsi tanısını genel anestezi endikasyonu olarak görmemiştir. Epilepsi hastalarının, gerekli önlem ve tedbirler alınmak şartıyla dental ofislerde tedavi edileceğ ${ }^{20}$, ihtiyac halinde genel anestezinin de uygun ortam ve koşullarda uygulanmak koşuluyla, güvenli olabileceği söylenebilir. ASA (American Society of Anesthesiology) sınıflamasına göre diyabet, hipertansiyon gibi sistemik rahatsızığı olan hastalarda genel anestezi ek problemi olmayanlara göre daha risklidir ${ }^{23}$. Bu nedenle, hastalar preoperatif dönemde iyi değerlendirilmelidir. Genel anestezi uygulaması dental işlemler için kaçınılmaz ise hastanın sistemik hastalıkları kontrol altına alınmaya çalışılmalı, optimum şartlar sağlandıktan sonra genel anestezi uygulanmalıdır. Ancak, bazen hastanın aşırı dental fobi ve stresin tansiyon hastalarında hipertansif atağa veya diyabet hastalarında kan şekeri düzeyinde yükselmeye sebep olabileceği unutulmamalıdır. Böyle durumlarda, genel anestezi uygulaması optimum şartlar sağlanmak koşuluyla alternatif bir yaklaşım olabilir. Bizım çalışmamızda, katılımcıların sistemik rahatsızlığı olan hastaları yüksek oranda lokal anestezi şartlarında tedavi etmeye çalıştıkları saptanmıştır.

Malign hipertermi; genellikle volatil anestezik tetiklediği, sarkoplazmik retikulumudan aşırı kalsiyum salınımı sonrası gelişen hipermetabolik bir durum, kas rijiditesi ve ölümle karakterize bir nörogenetik bir has talıktır. Konjenital kas hastalığı veya nöromusculer bozukluk olan hastalarda malign hipertermi riski yüksektir $^{24}$. Her ne kadar, spinal ve epidural anestezi gibi rejyonel anestezi uygulamalarının malign hiper- termi yatkınlığı olan hastalarda güvenli olduğu yaygın olarak kabul edilse de, tetrakain gibi ester yapılı bazı lokal anesteziklerin malign hipertermiyi tetikleyebileceği bildirilmiştir $^{25}$. Malign hipertermiye yatkınlığı olan hastalarda dental işlemler için amid tipi lokal anestezik kullanımının ester tipi lokal anesteziklere kıyasla daha güvenli olacağı da literatüre girmiş bir bilgidir ${ }^{26}$. Dolayısıyla konjenital kas hastalığı olan hastaları, genel anesteziye yönlendirirken dikkatli olunmalıdır. Zorunlu haller dışında mümkünse bu hastalarda lokal anesteziyi tercih etmek gerekir. Genel anestezi kaçınılmaz ise, anestezi uzmanı önerileri ile hareket edilmelidir. Bu anket çalışması da, katılımcıların malign hipertermi konusunda duyarlı olduklarını, çoğunluk itibari ile kas hastalığı olanların dental işlemlerini lokal anestezi altında gerçekleştirmeyi daha güvenli bulduklarını göstermiştir.

Çalışma sonuçlarımıza göre; Kayseri ili ve çevresindeki diş hekimlerinin çoğu dental tedavilerde genel anestezi uygulamaları, risk ve komplikasyonları konusunda yeterli düzeyde bilgi birikimi ve farkındalığa sahiptirler. Her ne kadar genel anestezinin işlem kolaylığı sağladığı düşüncesi hakim olsa da, katılımcılar öncelikli olarak lokal anesteziyi tercih etmekte, zorunlu hallerde ise hastaları kendi içerisinde değerlendirip karar vermek koşuluyla genel anesteziye yönlendir- mektedirler.

\section{KAYNAKLAR}

1. Leroy DV. History of Anesthetic Practice. In RD Miller ed. Anesthesia. Newyork. Churchill Livingstone 1994;9-19.

2. Kömerik N, Kırzıoğlu Z. Zihinsel engele sahip bireylerde ağız sağlığı. ] Dent Fac Atatürk Uni 2012;22:96-104.

3. Vargas Román Mdel $\mathrm{P}$, Rodríguez Bermudo $\mathrm{S}$, Machuca Portillo G. Dental treatment under 
general anesthesia: a useful procedure in the third millennium? Med Oral 2003;8:129-35.

4. Alcaino E, Kilpatrick NM, Smith ED. Utilization of day stay general anaesthesia for the provision of dental treatment to children in New South Wales, Australia. Int J Paediatr Dent 2000;10:206-12.

5. Carson $P$, Freeman R. Dental caries, age and anxiety: factors influencing choice for children attending for emergency dental care. Community Dent Oral Epidemiol 2001;29:30-6.

6. Wilson S. Pharmacologic behavior management for paediatric dental treatment. Paediatr Clin Noth Am 2000;47:1159-75.

7. Mehra P, Arya V. Temporomandibular joint arthrocentesis: outcomes under intravenous sedation versus general anesthesia. J Oral Maxillofac Surg 2015;73:834-42.

8. Saenz MC, Gomez ML, Goig MR, Cuesta US, Martin MI. Results of a major ambulatory oral surgery program using general inhalational anesthesia on disabled patients. Med Oral Patol Oral Cir Bucal 2009;14:e605-11.

9. Jankauskiene B, Virtanen JI, Kubilius R, Narbutaite J. Oral health-related quality of life after dental general anaesthesia treatment among children: a follow-up study. BMC Oral Health. 2014;4:81.

10. Lee PY, Chou MY, Chen YL, Chen LP, Wang CJ, Huang WH. Comprehensive dental treatment under general anesthesia in healthy and disabled children. Chang Gung Med J 2009;32:636-42.

11. Yoshida $H$, Ayuse $T$, Ishizaka $S$, Ishitobi $S$, Nogami $T$, Oi K. Management of exaggerated gag reflex using intravenous sedation in prosthodontic treatment. Tohoku J Exp Med 2007;212:373-8.

12. Cottrell JE. We care, therefore we are: anesthesiarelated morbidity and mortality: the 46th Rovenstine Lecture. Anesthesiology 2008;109:37788.

13. Roberts GJ, Hosey MT. Pharmacological management of pain and anxiety.In: Welbury RR, Duggal MS, Hosey MT eds. Paediatric Dentistry, 3th ed. United States. Oxford University Press Inc 2005:65-88.

14. Berini L, Gay C, Editores. Anestesia Odontologica. Madrid: Avances Médico-Dentales,S.L, 1997:27-45.

15. Ghezzi EM, Chávez EM, Ship JA. General anaesthesia protocol for the dental patient: emphasis for older adults. Spec Care Dent 2000;20:81-92.
16. Thyssen JP, Menné $T$, Elberling J, Plaschke P, Johansen JD. Hypersensitivity to local anaesthetics-- update and proposal of evaluation algorithm. Contact Dermatitis 2008;59:69-78.

17. Parekh S, Gardener C, Ashley PF, Walsh T. Intraoperative local anaesthesia for reduction of postoperative pain following general anaesthesia for dental treatment in children and adolescents. Cochrane Database Syst Rev 2014;23:12: CD009742.

18. Berroa F, Lafuente A, Javaloyes G, Cabrera-Freitag $\mathrm{P}$, de la Borbolla JM, Moncada $\mathrm{R}$, et al. The incidence of perioperative hypersensitivity reactions: a single-center, prospective, cohort study. Anesth Analg 2015;121:117-23.

19. Malamed SF. Emergency medicine in pediatric dentistry: preparation and management. J Calif Dent Assoc 2003;31:749-55.

20. Aragon CE, Burneo JG. Understanding the patient with epilepsy and seizures in the dental practice. J Can Dent Assoc 2007;73:71-6.

21. Gélisse $P$, Genton $P$, Coubes $P$, Tang NP, Crespel A. Can emotional stres trigger the onset of epilepsy? Epilepsy Behav 2015;48:15-20.

22. Zhao X, Wang X. Anesthesia-induced epilepsy: causes and treatment. Expert Rev Neurother 2014;14:1099-113.

23. Keats AS. The ASA classification of physical status-a recapitulation. Anesthesiology 1978;49:233-6.

24. Klingler $W$, Rueffert $H$, Lehmann-Horn $F$, Girard $T$, Hopkins PM. Core myopathies and risk of malignant hyperthermia. Anesth Analg 2009;109:1167-73.

25. Sheu CC, Tsai JR, Hung JY. Possible malignant hyperthermia during spinal anaesthesia with tetracaine. Anaesthesia 2007;62:200-1.

26. Minasian A, Yagiela JA. The use of amide local anesthetics in patients susceptible to malignant hyperthermia. Oral Surg Oral Med Oral Pathol 1988;66:405-15.

\section{Yazışma Adresi}

Dr. Dilek Günay CANPOLAT

Erciyes Üniversitesi Diş Hekimliği Fakültesi,

Ağız, Diş ve Çene Cerrahisi Hastanesi

C Blok 1. Kat Talas/Kayseri

Anesteziyoloji ve Reanimasyon Uzmanı

Tel: 03522076666 - 29183

e-mail: dgcanpolat@gmail.com 